\title{
A rare case of aberrant pancreas in the colon: choristoma of Bauhin's valve
}

A 48-year-old man with normal antenatal history was admitted to hospital with complaints of recurrent nonintensive pain on the right side. The patient had a medical history of Crohn's disease (remission) for the past 5 years.

Physical and laboratory examinations (including amylase, 45U/L) were unremarkable. Computed tomography scan revealed wall thickening of the distal ileum up to $0.4 \mathrm{~cm}$. Colonoscopy showed a nonepithelial lesion with a diameter of $0.3 \mathrm{~cm}$ and a smooth surface and regular capillary pattern on the lower lip of the Bauhin's valve (ileocecal valve) ( Fig. 1, - Video 1). Biopsy was performed and demonstrated mucous glands lying directly under the muscle plate, forming a nodular lesion covered with the usual histological structure of mucous membranes ( $\$$ Fig. 2 ). Paneth cells with bright red granular cytoplasm were found at the base of the crypts (normal for this location in the colon mucosa). Given the lack of available mucous glands in the colon submucosa, this modification is to be seen as a choristoma, and thus, the specimen was identified as a choristoma of the Bauhin's valve.

At the next stage, the patient underwent endoscopic resection of the lesion with a cold snare. There were no complications in the postoperative period. The patient was discharged on the second day after surgery.

Choristoma (heterotopia, pancreatic ectopia; aberrant pancreas) is a rare, in most cases asymptomatic congenital anomaly, characterized by the presence of a group of pancreatic cells/tissue in an atypical place without neural, vascular, or other anatomical connections with the main pancreas [1]. The first morphologically confirmed case of pancreatic heterotopy was published by Klob in 1859 and, more recently, detailed analysis of morphology and histology has

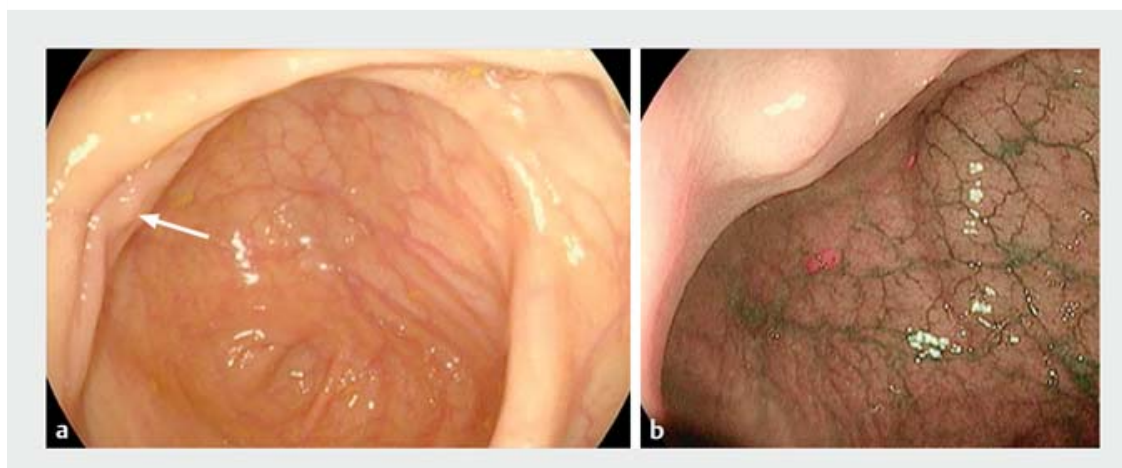

- Fig. 1 Colonoscopy photographs before biopsy demonstrated a nonepithelial lesion on the lower lip of the Bauhin's valve. a White-light imaging. b I-SCAN mode.

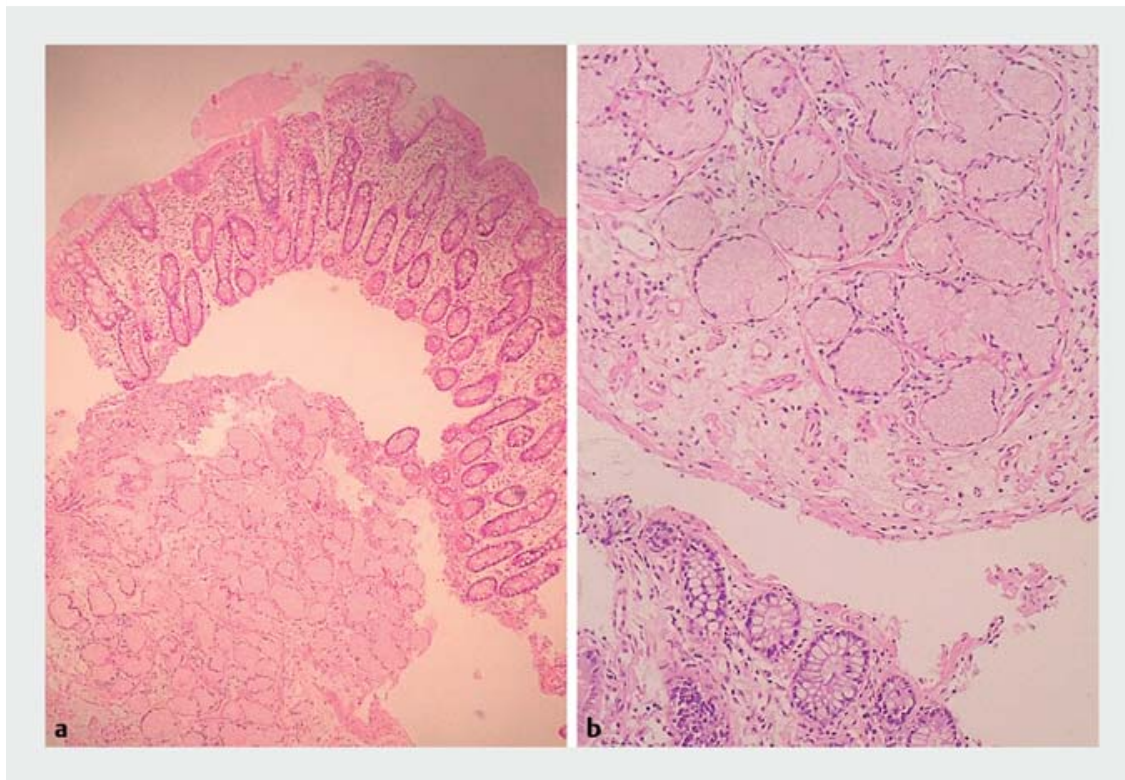

- Fig. 2 Histopathological section revealed groups of mucous glands surrounded by thin bundles of smooth muscle cells and located in the edematous stroma (hematoxylin and eosin stain). $\mathbf{a} \times 100$. $\mathbf{b} \times 250$.

been described [2]. Aberrant pancreas can be located in the stomach $(27.5 \%)$, duodenum (25.5\%), and colon (15.9\%) $[3,4]$. Rare localizations include biliary tract, liver, spleen, greater omentum, and lungs $[3,4]$.
We electronically searched PubMed (1984 - July 2019) for the keywords "choristoma colon" and found only 87 articles; for the keywords "choristoma Bauhin's valve" there are no data.

Endoscopy_UCTN_Code_CCL_1AD_2A J 


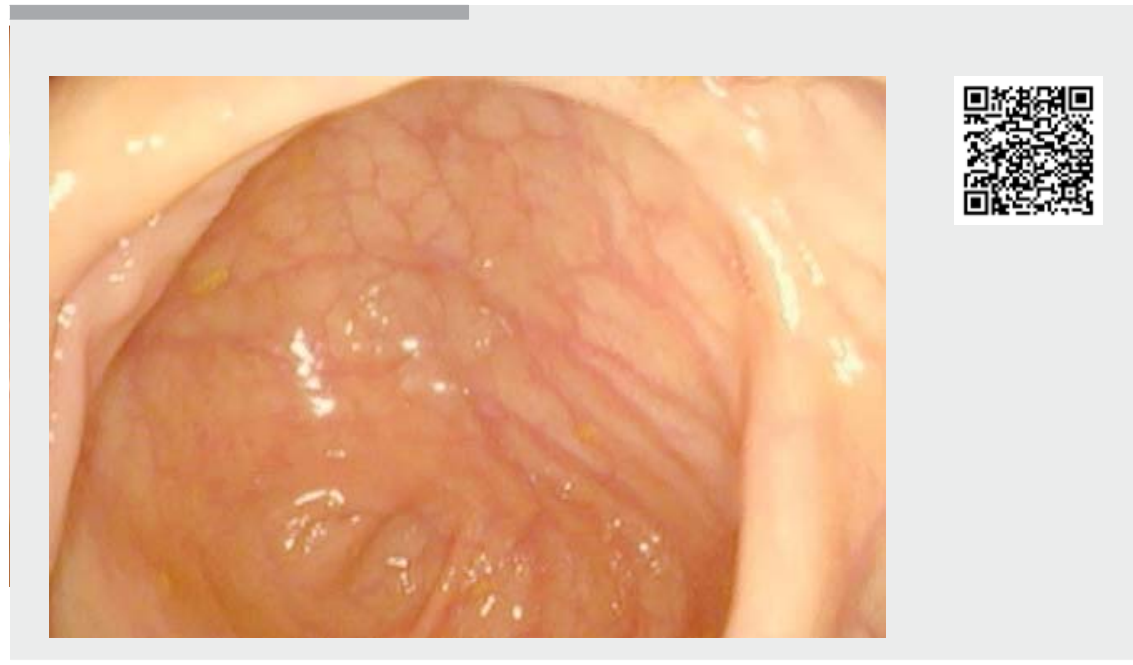

$\checkmark$ Video 1 Colonoscopy showing a nonepithelial lesion with a diameter of $0.3 \mathrm{~cm}$ and a smooth surface and regular capillary pattern.

\section{Competing interests}

None

The authors

Pavel V. Pavlov' ${ }^{1}$, Andrey P. Kiryukhin' ${ }^{1}$, Alexander S. Tertychnyi ${ }^{2}$, Yuri E. Kitsenko ${ }^{3}$

1 Endoscopy Unit, The Second University Clinic, I.M. Sechenov First Moscow State Medical University (Sechenov University), Moscow, Russia

2 Department of Pathology, I.M. Sechenov First Moscow State Medical University (Sechenov University), Moscow, Russia

3 Clinic of Coloproctology and Minimally Invasive Surgery, I.M. Sechenov First Moscow State Medical University (Sechenov University), Moscow, Russia
Corresponding author

Andrey P. Kiryukhin, MD, PhD

Endoscopy Unit, The Second University Clinic, I.M. Sechenov First Moscow State Medical University (Sechenov University), 1 build.1. Pogodinskaya St., Moscow, 119435, Russia Fax: +7-903-5066153

a.p.kiryukhin@gmail.com

\section{References}

[1] Lankisch PG, Banks PA. Pancreatitis. Berlin, Heidelberg: Springer; 1997

[2] Bromberg SH, Neto CC, Fernando A et al. Pancreatic heterotopias: clinicopathological analysis of 18 patients. Rev Col Bras Cir 2010; 37: 413-419
[3] Hirasaki S, Kubo M, Inoue A et al. Jejunal small ectopic pancreas developing into jejunojejunal intussusception: a rare cause of ileus. World J Gastroenterol 2009; 15: 3954 3956

[4] Sodhi KS, Fink AM. Education and imaging. Gastrointestinal: aberrant ileal pancreas causing intussusception. J Gastroenterol Hepatol 2009; 24: 322

Bibliography

DOI https://doi.org/10.1055/a-1022-4216

Published online: 25.10.2019

Endoscopy 2020; 52: E120-E121

(c) Georg Thieme Verlag KG

Stuttgart · New York

ISSN 0013-726X

\section{ENDOSCOPY E-VIDEOS}

https://eref.thieme.de/e-videos

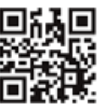

Endoscopy E-Videos is a free access online section, reporting on interesting cases and new

techniques in gastroenterological endoscopy. All papers include a high quality video and all contributions are freely accessible online.

This section has its own submission website at

https://mc.manuscriptcentral.com/e-videos 